\title{
CD147 knockdown improves the antitumor efficacy of trastuzumab in HER2-positive breast cancer cells
}

\author{
Lijuan Xiong ${ }^{1, *}$, Li Ding ${ }^{2, *}$, Haoyong Ning ${ }^{3, *}$, Chenglin Wu ${ }^{1}$, Kaifei Fu ${ }^{1}$, Yuxiao Wang ${ }^{1}$, \\ Yan Zhang ${ }^{4}$, Yan Liu ${ }^{2}$, Lijun Zhou ${ }^{1}$ \\ ${ }^{1}$ Central Laboratory, Navy General Hospital, Beijing 100048, P.R. China \\ ${ }^{2}$ The Third School of Clinical Medicine, Southern Medical University, Guangzhou, Guangdong, 510630, P.R.China \\ ${ }^{3}$ Department of Pathology, Navy General Hospital, Beijing 100048, P.R. China \\ ${ }^{4}$ Department of Surgery, Navy General Hospital, Beijing 100048, P.R. China \\ *These authors equally contributed to this work \\ Correspondence to: Lijun Zhou, e-mail: hzzhoulj@126.com \\ Keywords: CD 147, HER2, breast cancer, antibody drug resistance/sensitivity, trastuzumab efficacy \\ Received: January 13, $2016 \quad$ Accepted: May 04, 2016 \\ Published: June 23, 2016
}

\section{ABSTRACT}

Trastuzumab is widely used in the clinical treatment of human epidermal growth factor receptor-2 (HER2)-positive breast cancer, but the patient response rate is low. CD147 stimulates cancer cell proliferation, migration, metastasis and differentiation and is involved in chemoresistance in many types of cancer cells. Whether CD147 alters the effect of trastuzumab on HER2-positive breast cancer cells has not been previously reported. Our study confirmed that CD147 suppression enhances the effects of trastuzumab both in vitro and in vivo. CD147 suppression increased the inhibitory rate of trastuzumab and cell apoptosis in SKBR3, BT474, HCC1954 and MDAMB453 cells compared with the controls. Furthermore, CD147 knockdown increased expression of cleaved Caspase-3/9 and poly (ADP-ribose) polymerase (PARP) and decreased both mitogen-activated protein kinase (MAPK) and Akt phosphorylation in the four cell lines. In an HCC1954 xenograft model, trastuzumab achieved greater suppression of tumor growth in the CD147-knockdown group than in the shRNA negative control (NC) group. These data indicated that enhancement of the effect of trastuzumab on HER2-positive cells following CD147 knockdown might be attributed to increased apoptosis and decreased phosphorylation of signaling proteins. CD147 may be a key protein for enhancing the clinical efficacy of trastuzumab.

\section{INTRODUCTION}

Breast cancer is one of the major malignancies threatening women's health. Worldwide, approximately 1.2 million new cases of breast cancer are diagnosed, and approximately 500,000 women die of breast cancer each year. HER2 (ErbB2 or NEU), a member of the ErbB family of receptor tyrosine kinases (RTKs), is the main pathogenic gene in breast cancer; HER2 overexpression has been demonstrated in 20 to $30 \%$ of patients [1,2]. Trastuzumab (Herceptin), a humanized monoclonal antibody against HER2 developed by Genentech, was approved by the Food and Drug Administration (FDA) for the treatment high HER2-expression breast cancer in 1998. However, the objective response rate to trastuzumab is only $30 \%$, and most breast cancer patients with high HER2 expression do not respond to trastuzumab treatment [3, 4]. Hence, efforts to improve drug treatment efficacy have received widespread attention. The goals of these efforts have included elucidation of the underlying mechanisms [4], identification of the synergistic effects of new target proteins [5], and the construction of bispecific or multispecific antibodies.

CD147, or HAb18G, a transmembrane glycoprotein, is a member of the human immunoglobulin superfamily [6-8]. It promotes tumor invasion, growth and metastasis by stimulating matrix metalloproteinase (MMP) synthesis in neighboring fibroblasts [9] and inhibiting cell apoptosis [10]. In addition, it promotes chemoresistance in different 
cancer cell types, including breast cancer cells [11-15], by stimulating hyaluronan production [16]. In hepatocellular carcinoma (HCC) and breast cancer, CD147 increases multi-drug resistance-1 and MMP-11 expression [12, 17-19]. Moreover, CD147 correlates with epidermal growth factor receptor activity in association with tumor chemoresistance in a cancer stem cell-like cell line derived from breast cancer cells [20]. However, wheher CD147 is related to antibody drug efficacy has not yet been elucidated.

In this study, we investigated whether CD147 alters the efficacy of trastuzumab against HER2-positive cancer in both trastuzumab-sensitive and -resistant breast cancer cell lines via CD147 knockdown and preliminarily explored the underlying mechanism. We also assessed the effect of CD147 on the antitumor efficacy of trastuzumab in a breast cancer xenograft model. Our results may provide insights for improving the efficacy of trastuzumab in HER2-positive breast cancer patients.

\section{RESULTS}

\section{Verification of CD147 and HER2 expression in vivo}

CD147 is expressed at a high level in cancer tissues and at a low level in normal tissues [21]. CD147 and HER2 expression in 271 breast cancer samples, as demonstrated by streptavidin-alkaline phosphatase immunohistochemistry (S-P IHC) analysis, has been previously reported [22, 23]. Here, we also detected CD147 and HER2 expression in 10 clinical breast cancer tissue samples (including 9 HER2-positive samples) by IHC to provide a foundation for subsequent analyses. The staining results for one sample are presented in Figure 1 (the rest of the results are shown in Supplementary Figure S1). CD147 and HER2 were mainly expressed on membranes. According to our results, CD147 was highly expressed in HER2-positive breast cancer tissues, verifying that CD147 and HER2 are frequently simultaneously expressed in HER2-positive breast cancer tissues in vivo.

\section{Verification of CD147 and HER2 expression in HER2-positive cancer cells}

To further confirm the IHC results, we performed fluorescence-activated cell sorting (FACS) to analyze CD147 and HER2 expression in different HER2-positive breast cancer cell lines (Figure 2A, 2B). High CD147 expression and low HER2 expression were observed in JIMT-1 and HCC1954 cells, and moderate expression of both CD147 and HER2 was detected in SKBR3 cells. Further, moderate CD147 expression and high HER2 expression were observed in BT474 cells, and low expression of both CD147 and HER2 was found in
MDA-MB453 cells. We also detected CD147 expression in cancer cells by immunofluorescence (IF) and immunocytochemistry (ICC) (Figure 2C), demonstrating similar results as those described above in the four cell lines. According to the literature, HCC1954 and MDAMB453 are always regarded as trastuzumab-resistant cell lines, and BT474 and SKBR3 are regarded as trastuzumabsensitive cell lines. Therefore, we chose these four cell lines for further study.

\section{CD147 expression is decreased by specific siRNAs in HER2-positive breast cancer cells}

The effects of specific siRNAs (Table 1) on CD147 expression were first evaluated by real-time polymerase chain reaction (RT-PCR). The results indicated that CD147 expression was significantly decreased in the CD147si2- and CD147si3-treated groups compared with the CD147si1treated, control and siRNA NC groups in BT474, SKBR3, MDA-MB453 and HCC1954 cells (Figure 3A, $\leq \leq 0.01$ ). Western blot analysis also confirmed that CD147si2 and CD147si3 decreased the CD147 protein levels in the four cell lines (Figure 3B). Thus, we chose CD147si2 and CD147si3 to inhibit CD147 expression in further experiments.

\section{CD147 knockdown enhances the inhibitory effect of trastuzumab in HER2-positive cancer cells}

To further understand the role of CD147, we investigated whether the suppression of CD147 expression by two specific siRNAs altered the response of HER2positive cancer cells to trastuzumab using different concentrations and treatment times. The morphologies and numbers of SKBR3, BT474, HCC1954 and MDA-MB453 cells were altered following trastuzumab treatment for $96 \mathrm{~h}$. Here, we only display the changes in SKBR3 and HCC1954 cells as representatives (Figure 4A). First, we examined the responses of the four cell lines to treatments with different concentrations of trastuzumab for $96 \mathrm{~h}$ by CCK- 8 assay (Figure 4B) to determine the optimal concentration. Interestingly, at $0 \mu \mathrm{g} / \mathrm{mL}$ trastuzumab, siRNA-mediated silencing of CD147 improved the responses of the resistant cell lines HCC1954 and MDA-MB453 to trastuzumab compared with the control cells (parental and siRNA NCtreated cells), whereas the sensitive cell lines SKBR3 and BT474 displayed the opposite responses, although no significance differences were detected compared with the controls in the four cell lines. However, starting at $0.1 \mu \mathrm{g} /$ $\mathrm{mL}$ trastuzumab, the CD147-knockdown-plus-trastuzumab treatment significantly inhibited cell proliferation in a dosedependent manner compared with the CD147-knockdown or trastuzumab treatment alone in both the resistant and sensitive cell lines $(\mathrm{p}<0.05$ in SKBR3, HCC1954 and MDA-MB453 cells; $\mathrm{p}<0.001$ in BT474 cells), although the sensitive SKBR3 and BT474 cells maintained strong reactions to trastuzumab treatment alone, while the resistant HCC1954 and MDA-MB453 cells displayed weak reactions 
There were no significant differences in the treatment responses between the two control groups in the four cell lines. Following treatment with $10 \mu \mathrm{g} / \mathrm{mL}$ trastuzumab, the inhibition rates were approximately $50 \%$ in the CD147knockdown groups of SKBR3 and BT474 cells; therefore, a concentration of $10 \mu \mathrm{g} / \mathrm{mL}$ was used in subsequent experiments, except for the HCC1954 and MDA-MB453 cell treatments, for which $100 \mu \mathrm{g} / \mathrm{mL}$ was used.

Then, time-dependent analysis was performed the four cell lines (Figure 4C). For each treatment time, the trends in cell proliferation were similar to those observed in dose-dependent analysis in the four cell lines. The only difference was that the inhibition rates in the CD147knockdown groups were markedly increased compared with those in the control groups of BT474 and SKBR3 cells $(\mathrm{p}<0.001)$ and HCC1954 cells $(\mathrm{p}<0.05)$ following the 3-day treatment, whereas in MDA-MB453 cells, such enhancement was observed following the 4-day treatment $(p<0.01)$. No significant differences in the inhibition rates were noted between the siRNA NC and control groups in the four cell lines.

These results suggest that CD147 knockdown and trastuzumab have an additive effect on inhibition of HER2-positive breast cancer cell viability.

\section{CD147 knockdown induces HER2-positive cancer cell apoptosis under trastuzumab treatment}

We also assessed apoptosis of SKBR3, BT474, HCC1954 and MDA-MB453 cells following trastuzumab treatment using Annexin V (AV) and propidium iodide (PI) staining. Here, we only present the AV and PI staining of SKBR3 and HCC1954 cells as representatives of sensitive and resistant cells, respectively (Figure 5A). Apoptosis was increased in the CD147-knockdown and CD147-knockdown-plus-trastuzumab groups compared with the control groups in the four cell lines (Figure 5B). Furthermore, only CD147-knockdown treatment notably enhanced apoptosis compared with the control groups especially in SKBR3 and BT474 cells. Under trastuzumab treatment alone, apoptosis was unpredictably strongly increased in the sensitive SKBR3 and BT474 cells, whereas it was markedly decreased in the resistant HCC1954 $(\mathrm{p}<0.05)$ and MDA-MB453 $(\mathrm{p}<0.05)$ cells compared with control cells. Moreover, compared with CD147-knockdown treatment alone, CD147-knockdown-plus-trastuzumab treatment increased apoptosis in SKBR3 $(\mathrm{p}<0.01)$ and HCC1954 $(p<0.05)$ cells, and this result was not observed

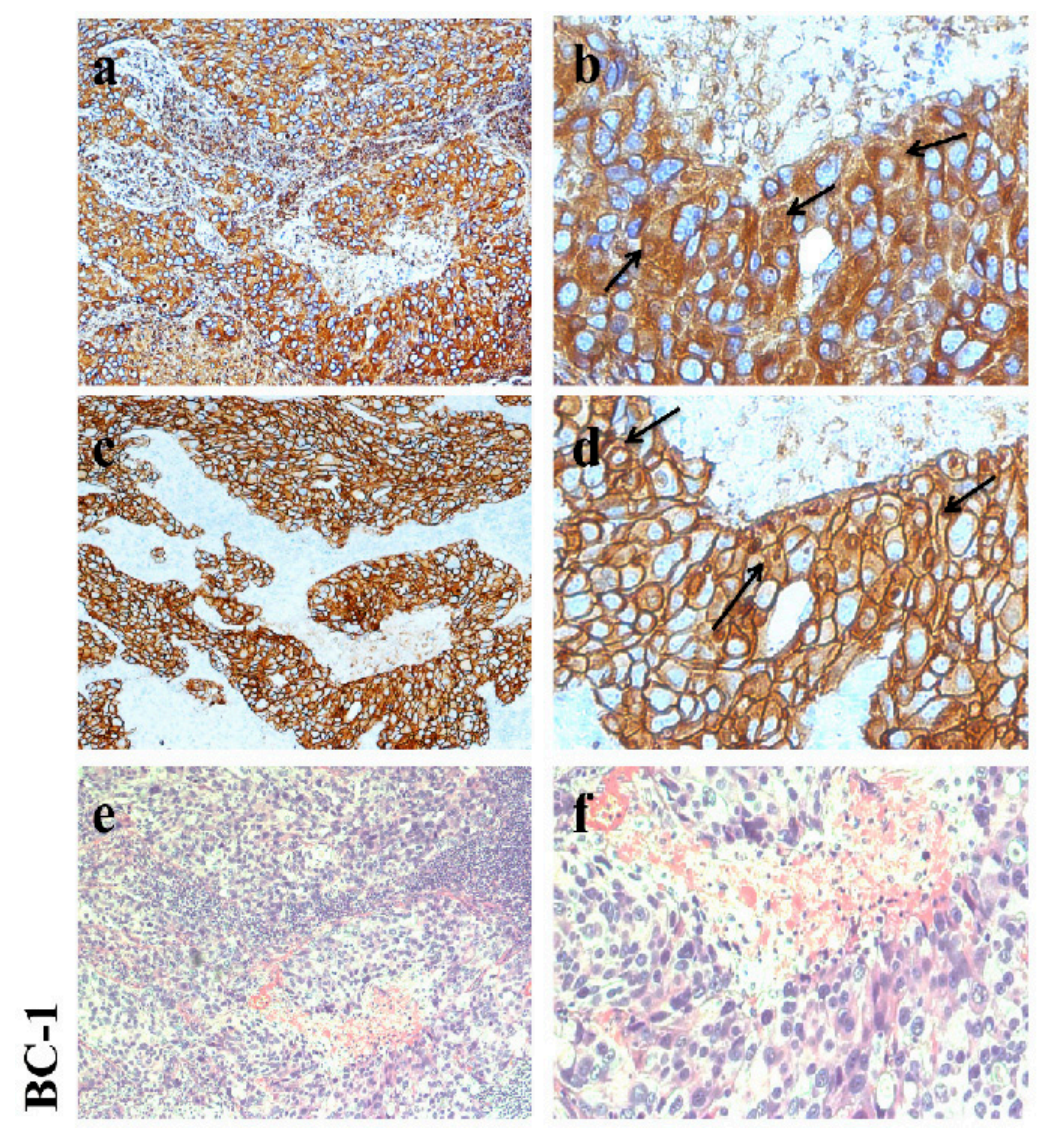

Figure 1: Immunohistochemical analysis of CD147 and HER2 expression in HER2-positive breast cancer. a, b. CD147 expression in breast cancer. c, d. HER2 expression in breast cancer. e, f. Hematoxylin-eosin (HE) staining. Left: 100× magnification; and right: $400 \times$ magnification. 


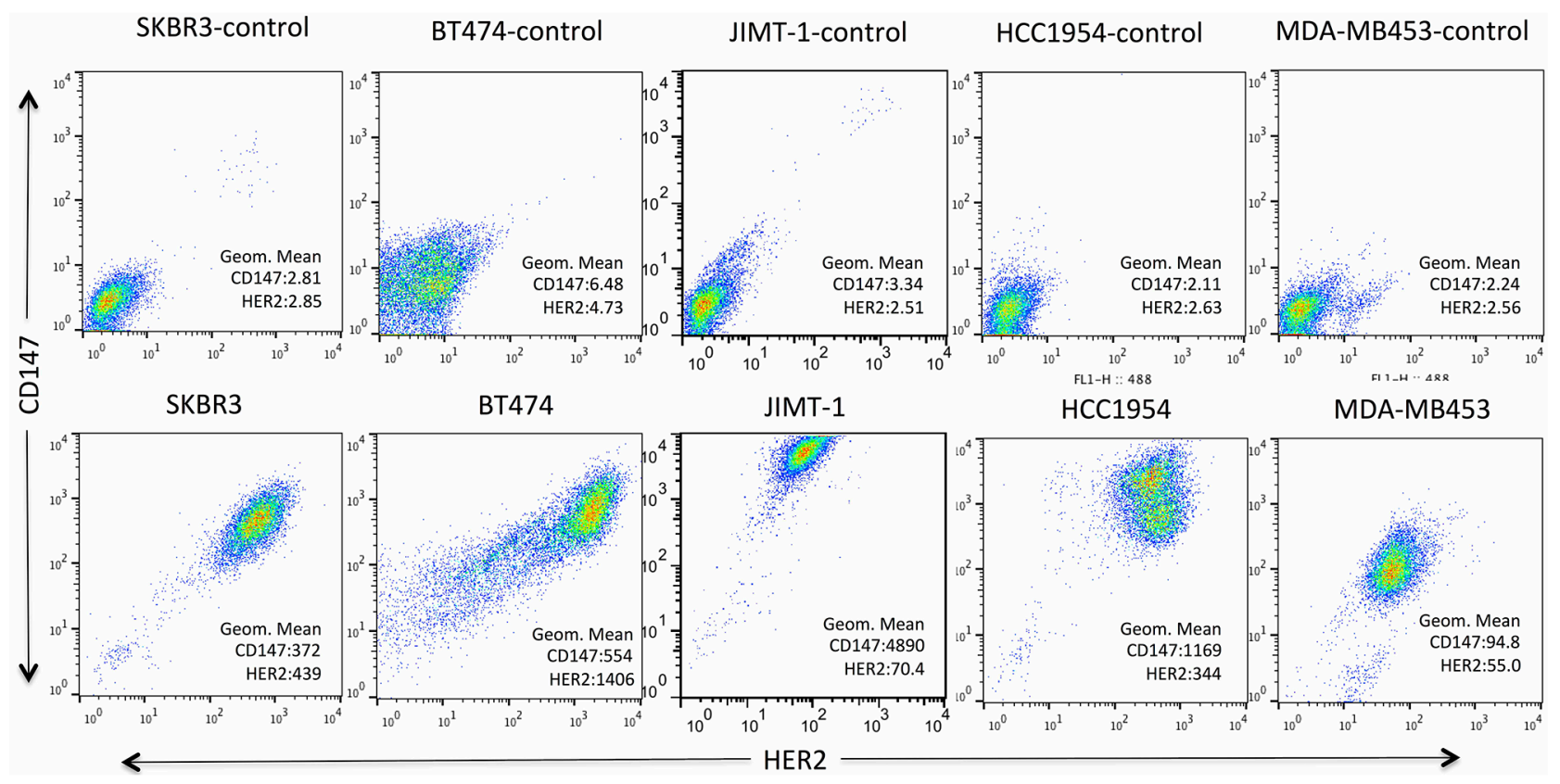

B

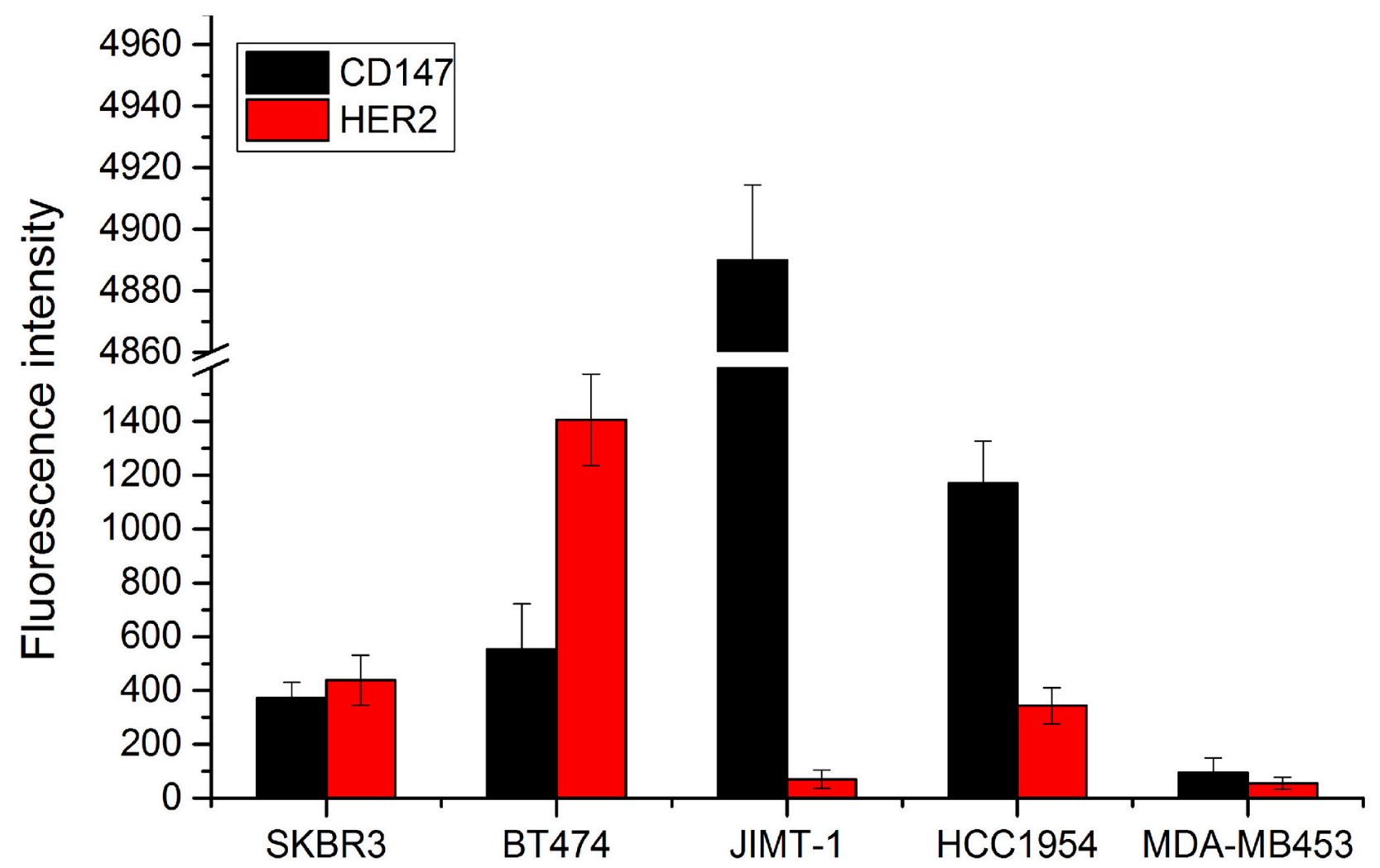

Figure 2: CD147 and HER2 expression in different HER2-positive cancer cell lines. A. and B. CD147 and HER2 protein expression in cancer cells, as measured by FACS. (Continued) 
C
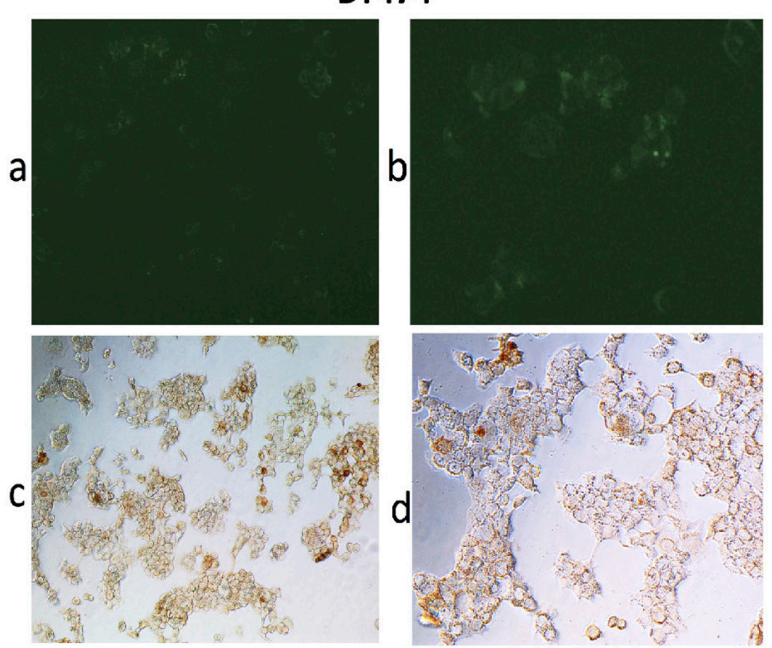

HCC1954
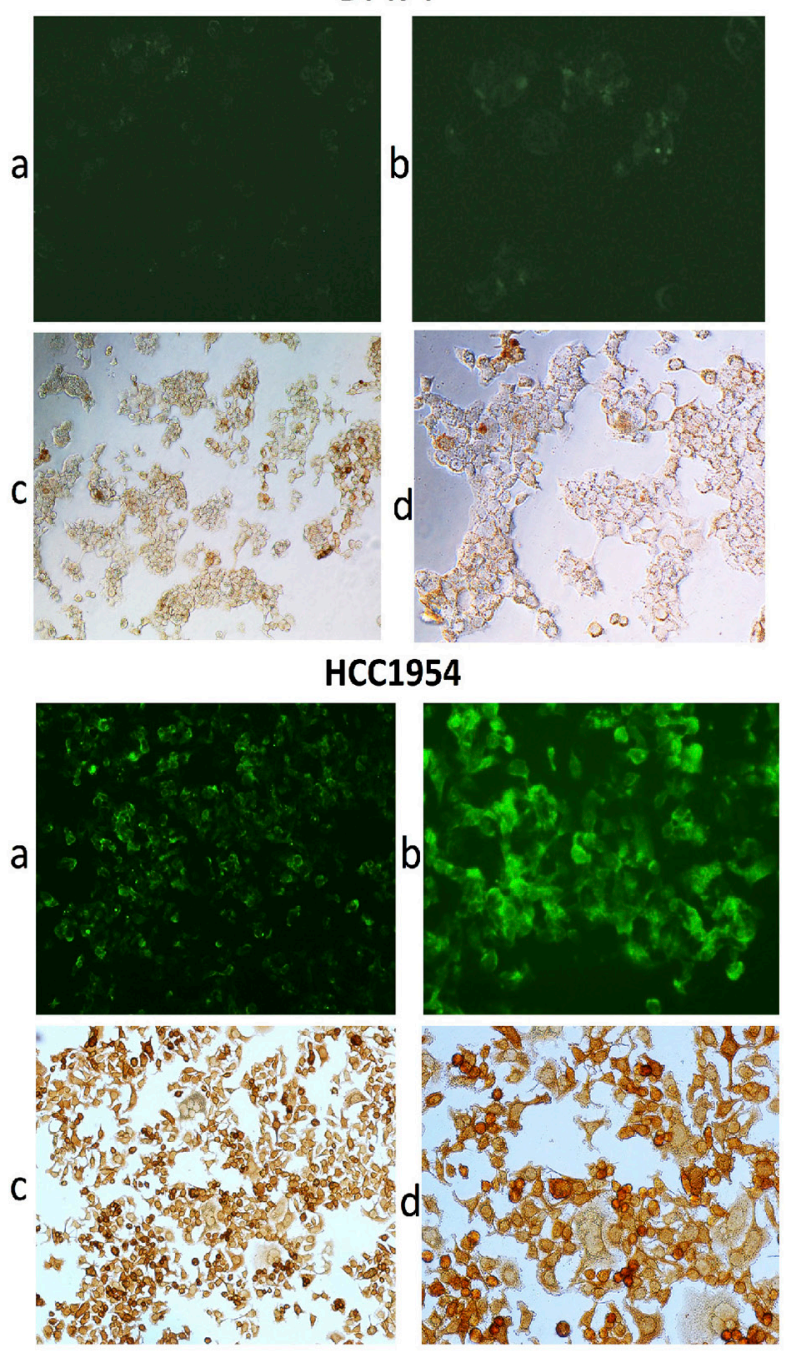
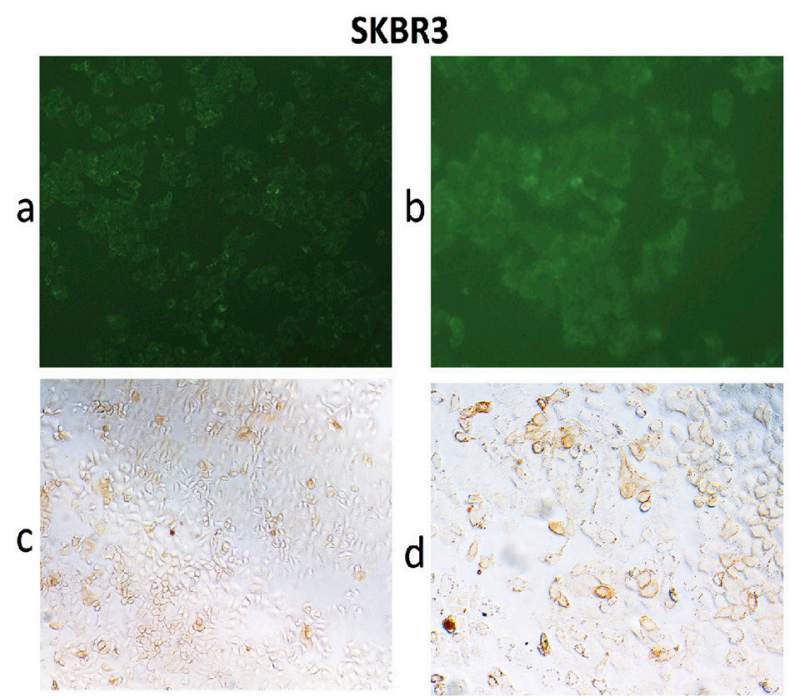

MDA-MB453
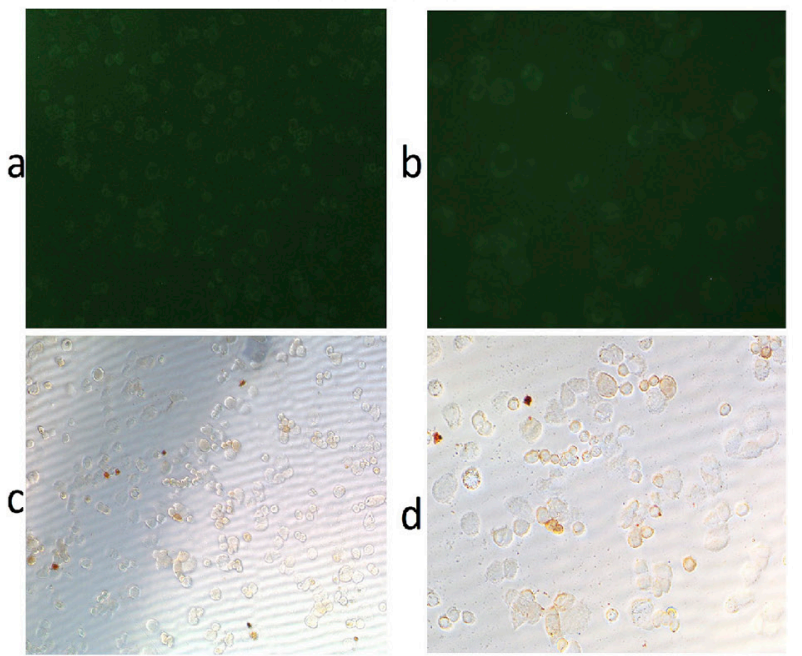

Figure 2: (Continued) CD147 and HER2 expression in different HER2-positive cancer cell lines. C. CD147 protein expression in BT474, SKBR3, HCC1954 and MDA-MB453 cells; a and b were detected by IF under 100× and 200× magnification; and c and $\mathrm{d}$ were detected by ICC under $100 \times$ and $200 \times$ magnification.

in BT474 or MDA-MB453 cells. However, compared with trastuzumab treatment alone, CD147-knockdown-plustrastuzumab treatment significantly increased apoptosis in the four cell lines. These findings indicated that inhibition of CD147 resulted in high rates of apoptosis in SKBR3 and BT474 cells and especially in trastuzumab-resistant HCC1954 and MDA-MB453 cells, which might be the primary reason that CD147 knockdown improved the efficacy of trastuzumab. No significant differences in apoptosis were noted between the siRNA NC and parental cell groups in the four cell lines.

Furthermore, we detected the levels of apoptotic proteins in the four cell lines (Figure 5C). Consistent with the above results, cleaved Caspase- $3 / 9$ and cleaved PARP were increased only in the CD147-knockdown and CD147-knockdown-plus-trastuzumab treatment groups compared with the control groups, regardless of trastuzumab treatment. In particular, the levels of cleaved Caspase-3/9 were markedly altered in SKBR3 cells, in addition to the levels of cleaved Caspase-9 and PARP in BT474 and MDA-MB453 cells and those of cleaved Caspase-3 and PARP in HCC1954 cells. There were no significant differences in the levels of apoptotic proteins between the two control groups in the four cell lines.

\section{Inhibition of CD147 decreases MAPK and/ or Akt phosphorylation during trastuzumab treatment in different HER2-positive breast cancer cells}

The MAPK/Erk or PI3K/Akt pathway is the primary downstream signaling pathway inhibited by trastuzumab in HER2-positive cancer cells [4]. Thus, we examined changes in the phosphorylation of MAPK and Akt before 
Table 1: Sequences of the designed CD147-specific siRNAs

\begin{tabular}{lc}
\hline siRNA & Sequence \\
\hline CD147si1 & GAGGUGCUGGUGCUGGUCACCAUCA \\
CD147si2 & AGUGAAGGCUGUGAAGUCGUCAGAA \\
CD147si3 & UCCGAGAGCAGGUUCUUCGUGAGUU \\
siRNA negative control & Stealth siRNA negative control \\
\hline
\end{tabular}

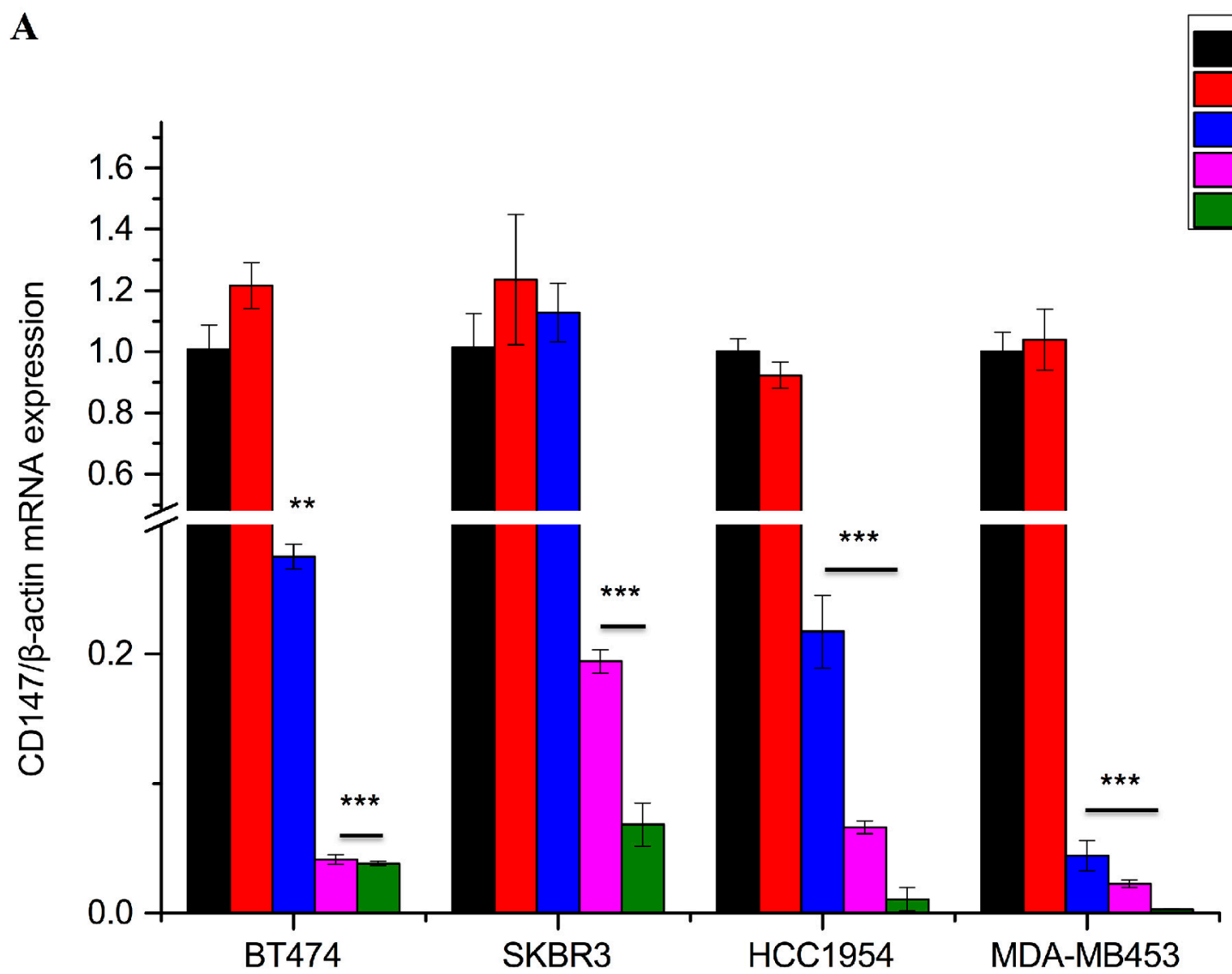

B

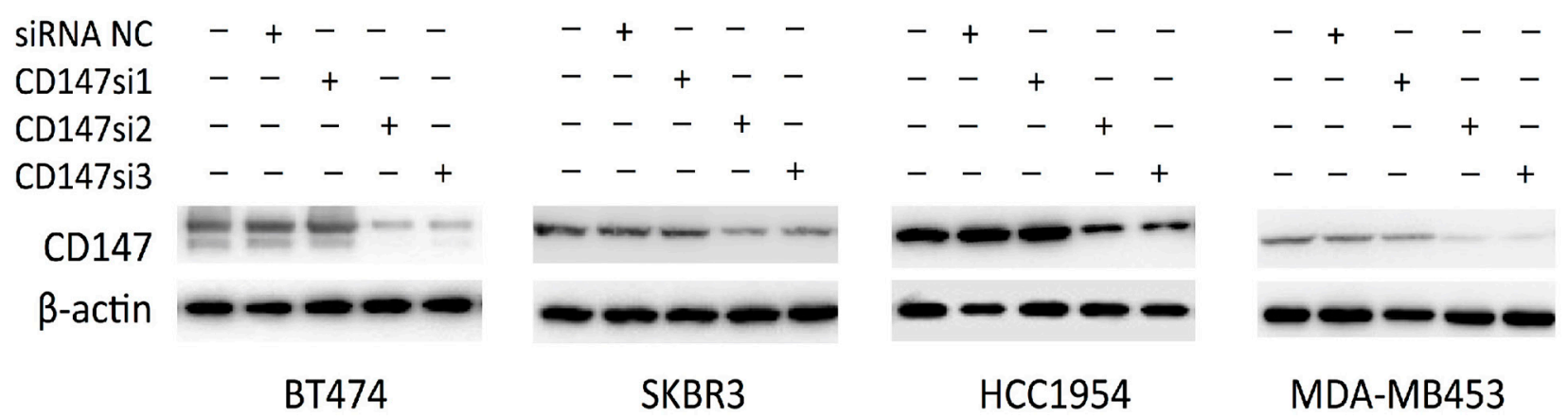

Figure 3: CD147 mRNA and protein expression levels were reduced by specific siRNAs. A. CD147 mRNA expression was detected by real-time PCR in different cell lines; $\beta$-actin was used as a normalization control. Inhibition of greater than $80 \%$ was regarded as effective siRNA interference. ${ }^{*} \mathrm{p}<0.05,{ }^{*} \mathrm{p}<0.01$ and $* * * \mathrm{p}<0.001$ compared with control. B. CD147 protein expression was detected by Western blotting in different cancer cells. 
A
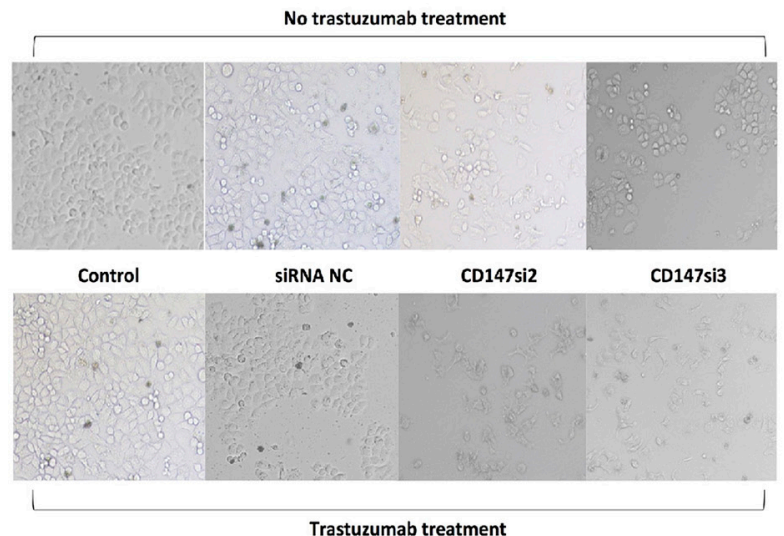

Trastuzumab treatment

B
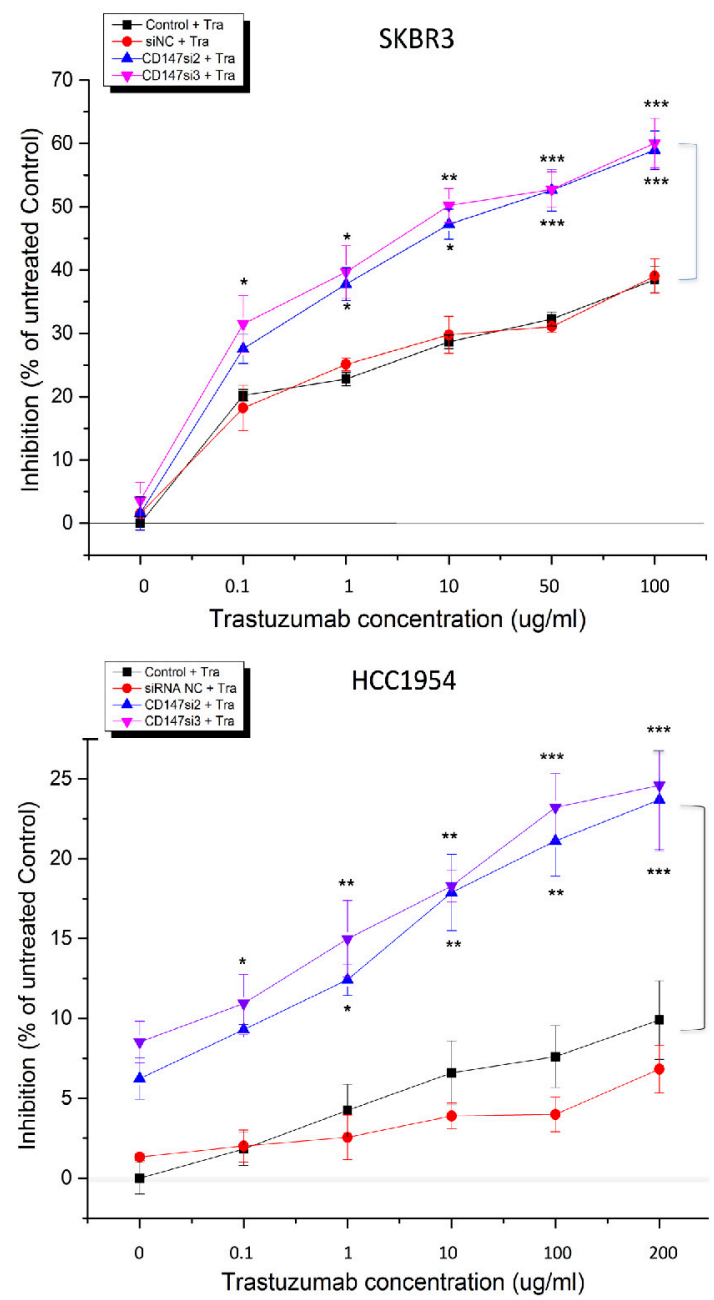

HCC1954

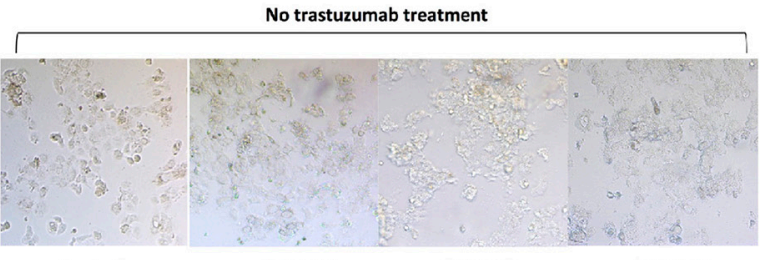

SIRNA NC

CD147si2

CD147si3

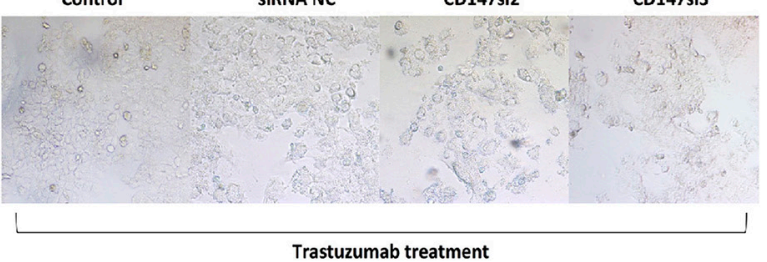

Trastuzumab treatment
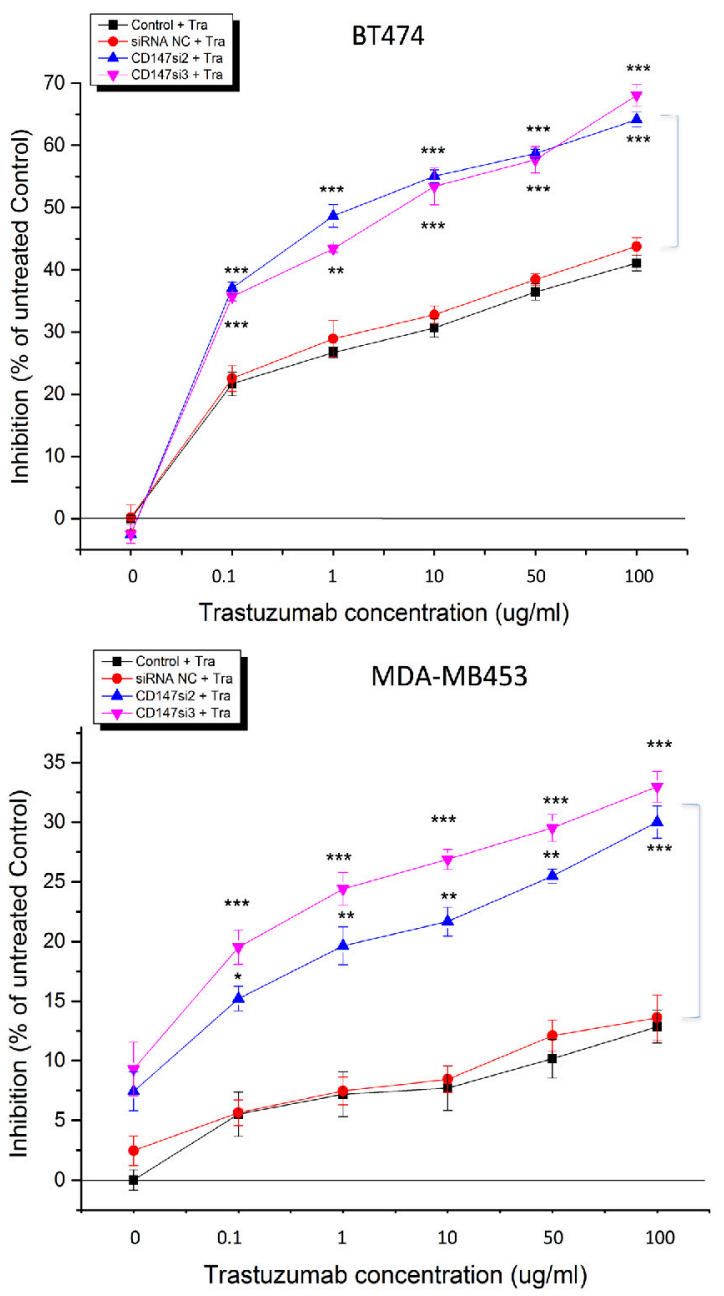

Figure 4: CD147 knockdown decreases cell viability in HER2-positive breast cancer in vitro after trastuzumab treatment. A. Changes in the morphologies and numbers of HER2-positive cancer cells after treatment of SKBR3 and HCC1954 cells with 10 and $200 \mu \mathrm{g} / \mathrm{mL}$ trastuzumab, respectively, for 4 days $(100 \times$ magnification). Note: a trastuzumab concentration of $0 \mu \mathrm{g} / \mathrm{mL}$ was used for the treatment with CD147 siRNA alone. B. Trastuzumab inhibition of cell viability, as measured by CCK-8 assay, occurred in a dosedependent manner after 4 days of treatment with trastuzumab at five different concentrations. (Continued) 
C
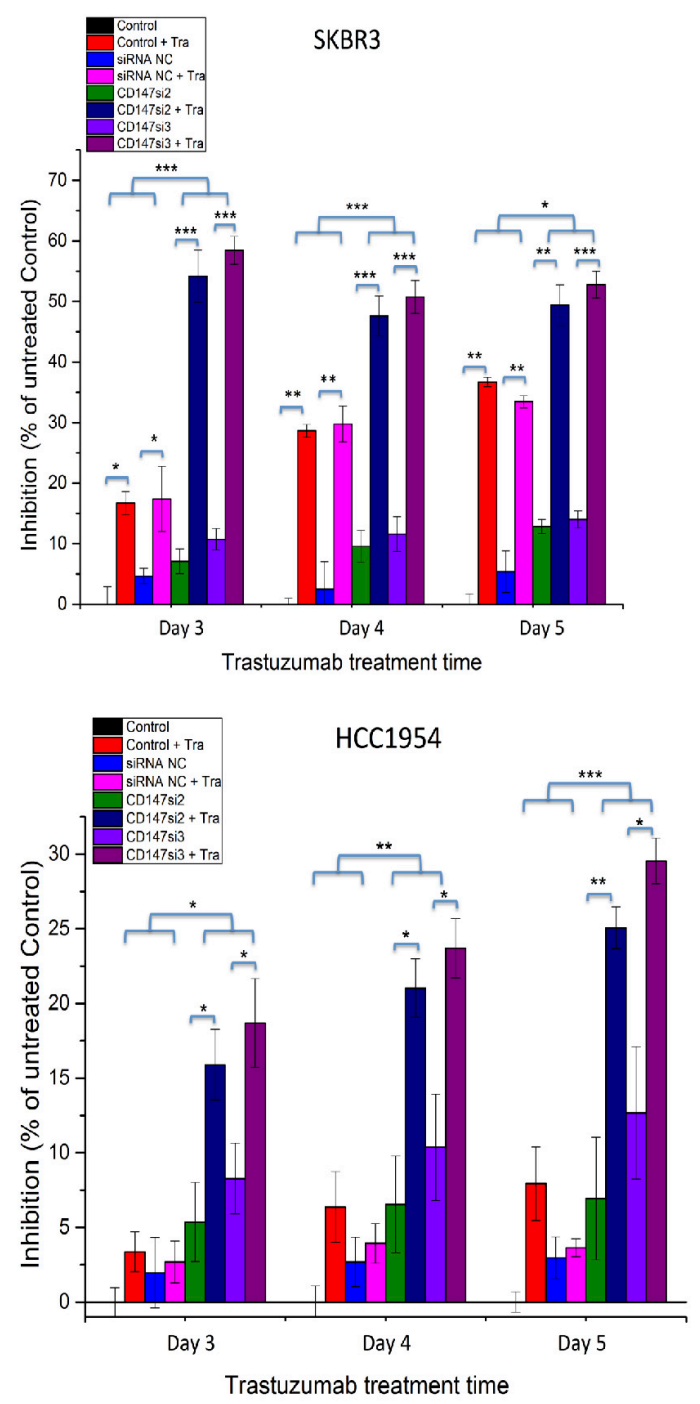
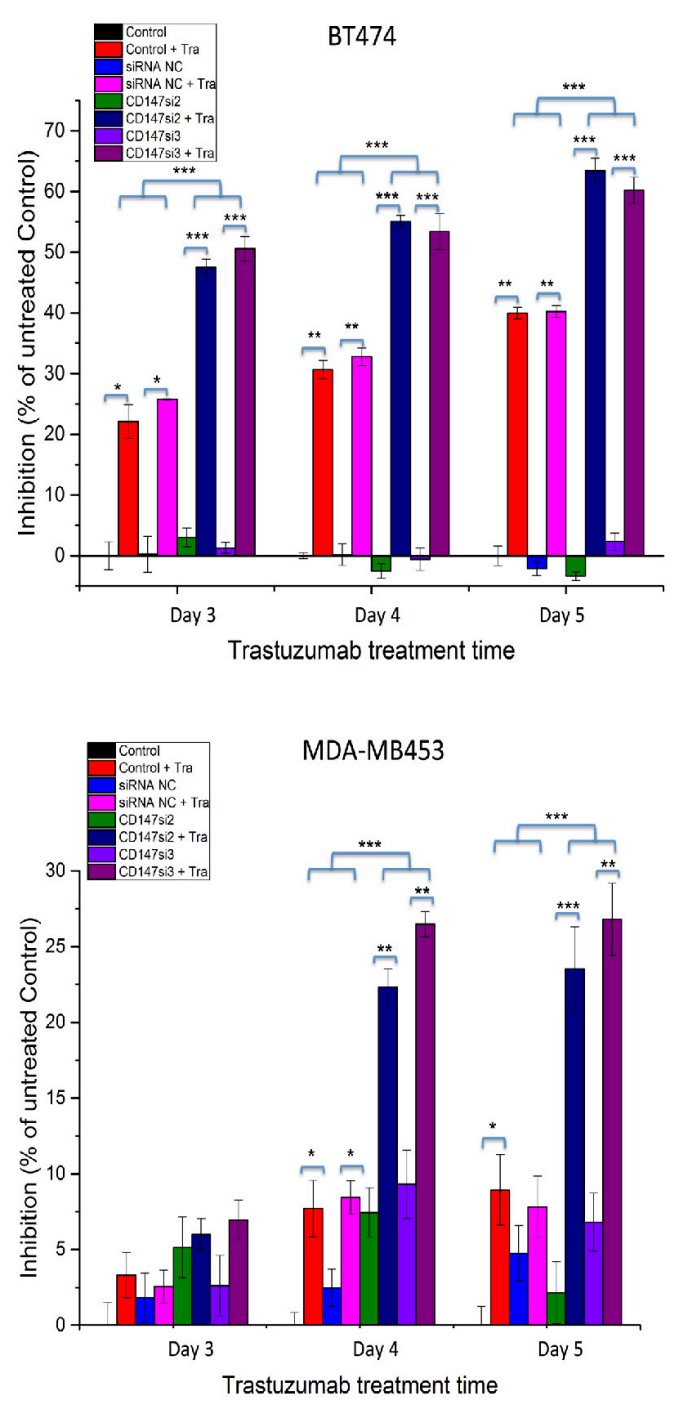

Figure 4: (Continued) CD147 knockdown decreases cell viability in HER2-positive breast cancer in vitro after trastuzumab treatment. C. Trastuzumab inhibits cell viability in a time-dependent manner. The data are presented as the mean \pm standard error of the mean (SEM) of three independent experiments. ${ }^{*} \mathrm{p}<0.05,{ }^{*} \mathrm{p}<0.01$ and ${ }^{* * *} \mathrm{p}<0.001$ vs. controls.

and after trastuzumab treatment for $1 \mathrm{~h}$ in SKBR3, BT474, HCC1954 and MDA-MB453 cells. As shown in Figure 6, CD147-knockdown or trastuzumab treatment alone decreased MAPK phosphorylation compared with the untreated control groups in the four cell lines. Moreover, CD147-knockdown-plus-trastuzumab treatment dramatically decreased MAPK phosphorylation compared with CD147-knockdown or trastuzumab treatment alone. No significant differences were observed between the siRNA NC and parental cell groups in the four cell lines with or without trastuzumab treatment.

The same decreasing trend in Akt phosphorylation was observed in BT474, SKBR3 and HCC1954 cells regardless of whether CD147-knockdown, trastuzumab or CD147-knockdown-plus-trastuzumab treatment was applied. However, little or no change in Akt phosphorylation was observed in the MDA-MB453 control groups after drug treatment alone; surprisingly, a decrease in Akt phosphorylation was observed following CD147-knockdown or CD147-knockdown-plus-trastuzumab treatment. There were no significant differences in Akt phosphorylation between the two control groups in the four cell lines with or without trastuzumab treatment.

\section{CD147 knockdown enhances the antitumor efficacy of trastuzumab in a breast cancer xenograft model}

The therapeutic efficacy of trastuzumab following CD147 suppression was examined in nude mice bearing established HCC1954-shRNA NC and HCC1954-sh483 xenograft tumors. Here, HCC1954-shRNA NC and 
A

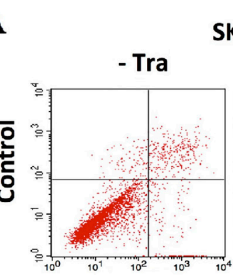

SKBR3
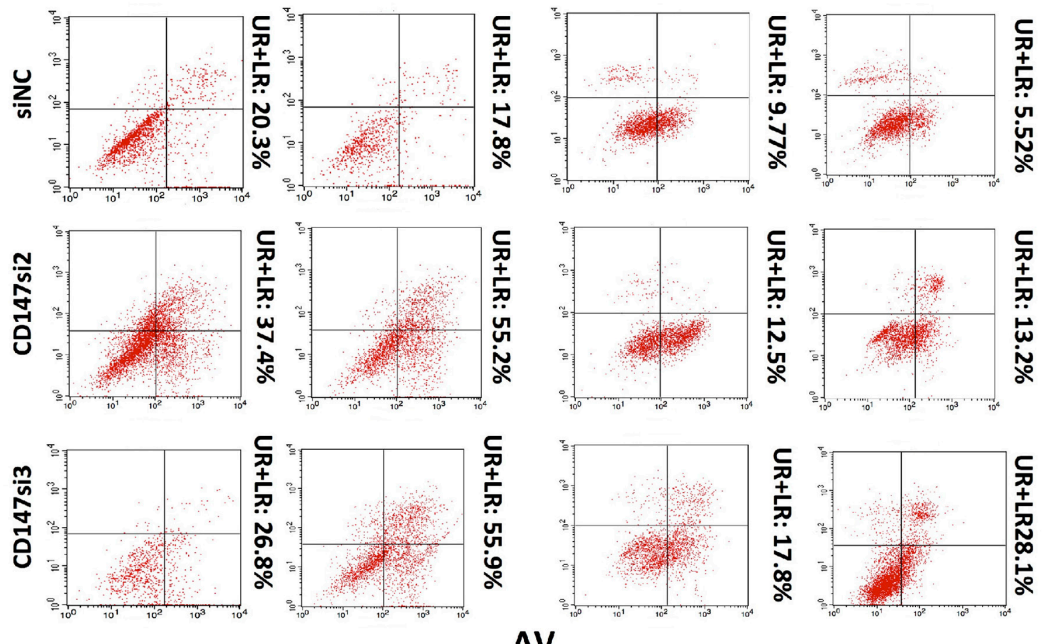

PI

B

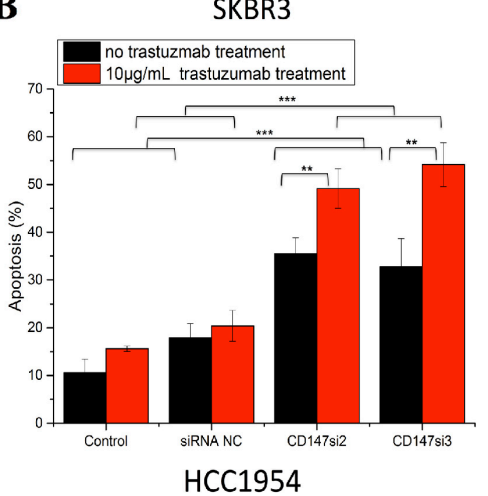

HCC1954

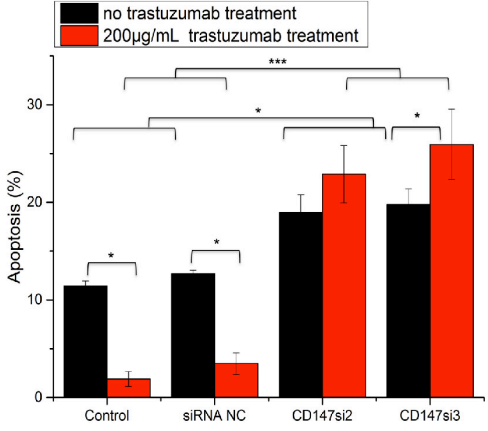

BT474

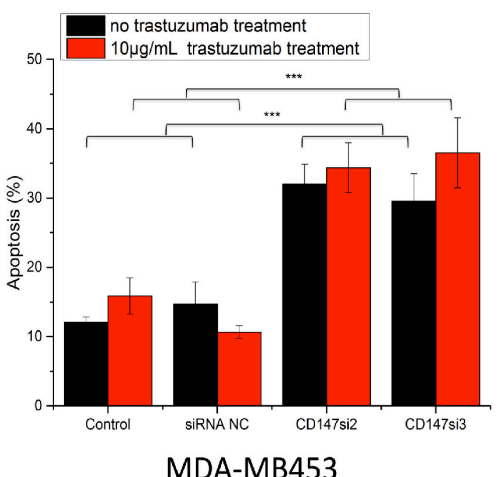

MDA-MB453

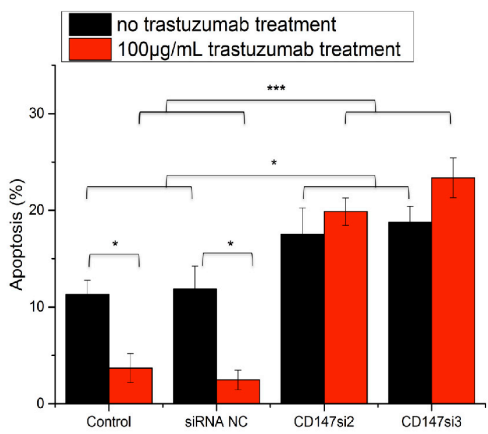

Figure 5: CD147 knockdown alters cell apoptosis in HER2-positive cancer in vitro after trastuzumab treatment. A. Cell apoptosis was measured by FACS after treatment of two HER2-positive cancer cell lines with 10 or $200 \mu \mathrm{g} / \mathrm{mL}$ trastuzumab for two days. For each cell line, no trastuzumab treatment is presented on the left, and trastuzumab treatment is presented on the right. B. Apoptosis was altered after the different treatments in the four HER2-positive breast cancer cell lines. (Continued) 

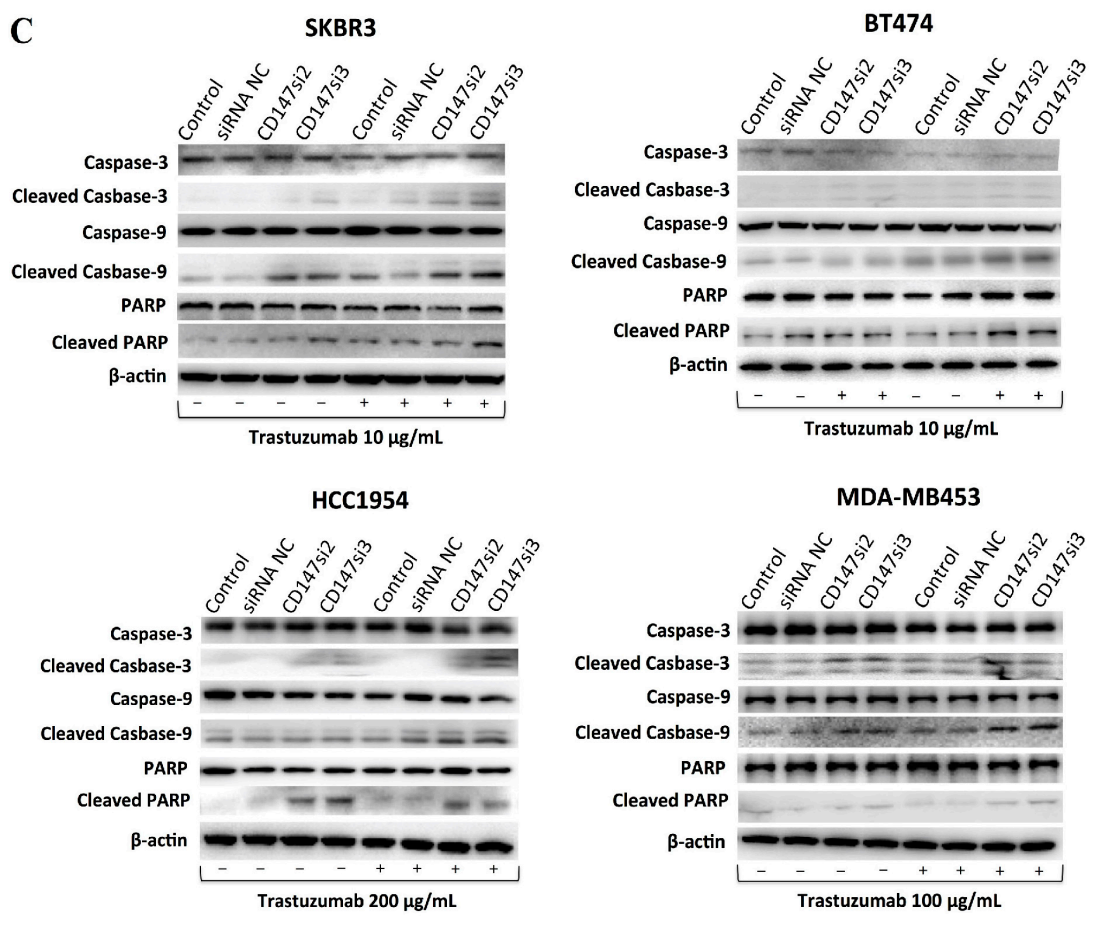

Figure 5: (Continued) CD147 knockdown alters cell apoptosis in HER2-positive cancer in vitro after trastuzumab treatment. C. Expression of apoptotic proteins was examined by Western blotting. The third and fourth lanes corresponded to the CD147siRNA treatment alone. The data are presented as the mean \pm SEM of more than three independent experiments. ${ }^{*} \mathrm{p}<0.05,{ }^{* *} \mathrm{p}<0.01$ and $* * * \mathrm{p}<0.001$ vs. controls.

HCC1954-sh483 cells were screened from stable CD147 knockdown cell lines established in HCC1954 cells using the shRNA interference method (Supplementary Figure S2). Trastuzumab exhibited increased suppression of tumor growth in the CD147-knockdown group compared the shRNA NC group in the HCC1954 xenograft model (Figure 7). Notably, based on the IHC results in tumor tissues, CD147 expression was suppressed in CD147knockdown group compared with shRNA NC group (Figure 7A), in accordance with the in vitro results (Supplementary Figure S3). Moreover, CD147-knockdownplus-trastuzumab treatment exhibited greater efficacy in inhibiting HCC1954 tumor growth than trastuzumab or CD147-knockdown treatment alone (Figure 7B). Specifically, compared with no treatment in the shRNA NC group, CD147-knockdown-plus-trastuzumab treatment resulted in $38.5 \%$ regression of HCC1954 tumors ( $\mathrm{p}<0.01)$, and CD147-knockdown treatment alone caused 15\% regression $(p<0.05)$, whereas the trastuzumab treatment alone resulted in no significant regression. These results indicated that CD147 knockdown improved the suppressive effect of trastuzumab on tumor growth in vivo.

\section{DISCUSSION}

Trastuzumab is widely used to prolong the survival of HER2-positive breast cancer patients, but a low objective response rate and the appearance of resistance have been reported $[3,4]$. These findings prompted us to identify novel ways to improve the efficacy of trastuzumab treatment in trastuzumab-responsive and unresponsive patients. CD147 is an important molecule in cancer [21], and different CD147 expression levels may have different clinical significance. Overexpression is always correlated with poor prognosis in certain cancers [24-29]. However, few reports have demonstrated a link between CD147 and trastuzumab treatment in HER2-positive breast cancer cells. Therefore, we first specifically detected CD147 expression and demonstrated that its knockdown improved the efficacy of trastuzumab in HER2-positive cancer cells. Our results were consistent with those of previous studies of CD147 expression in cancer cells using western blotting [30], and serve as a foundation for further analyses of relative CD147 expression. CD147-knockdownplus-trastuzumab treatment significantly inhibited cell proliferation and induced cell apoptosis in vitro and significantly improved the response of HER2-positive breast cancer cells to trastuzumab in vivo compared with the controls. These results indicate that inhibition of CD147 may be a new strategy for increasing the efficacy of trastuzumab in the clinical setting.

Next we preliminarily examined how CD147 knockdown improves the efficacy of trastuzumab. One hypothesis involved altered apoptosis of SKBR3, BT474, HCC1954 and MDA-MB453 cells in response to trastuzumab treatment. Caspase-3/9 and PARP cleavages, 
as well as AV and PI staining, were enhanced in the CD147knockdown groups compared with the control groups, indicating that CD147 has an important role in tumor cell apoptosis. CD147 has been reported to play similar roles in HCC [10, 31-33], head and neck squamous cell carcinomas [34], non-small cell lung carcinoma (NSCLC) [35], and ovarian cancer [36]. Following CD147 knockdown, Caspase-3 is activated in HCC cells [10]; further, increased Caspase-3 and PARP cleavages occur in human leukemic monocyte lymphoma U937 cells [37], whereas the addition of CD147 to melanoma cell lines has been shown to result in a decrease in Caspase-3/7 activity [38]. However, the effect of trastuzumab on cell apoptosis has not been well studied in recent years. Here, we determined the rates of trastuzumab-induced apoptosis in four parental HER2positive cancer cell lines. We found that trastuzumabinduced apoptosis was decreased in the parental SKBR3 and BT474 cells, similar to previous studies [39, 40], and

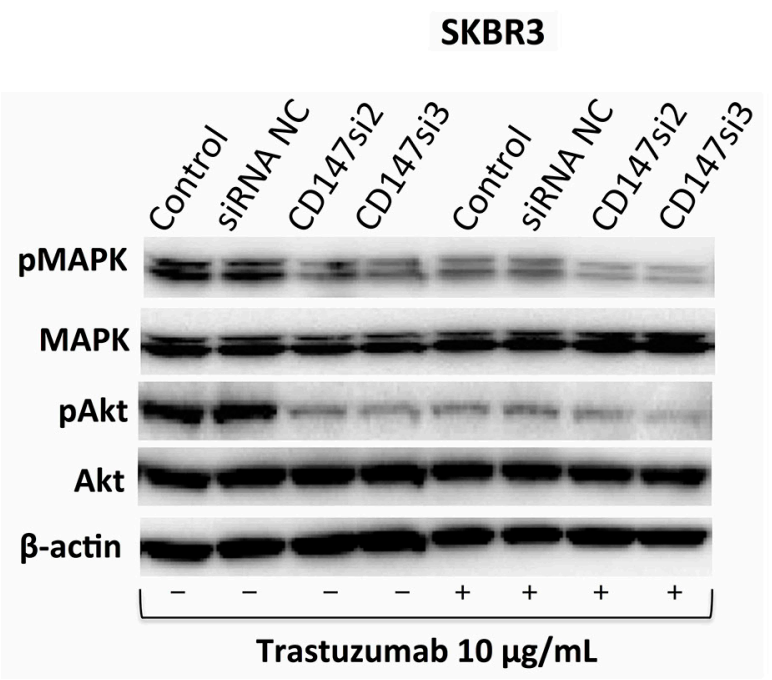

\section{SKBR3}

HCC1954

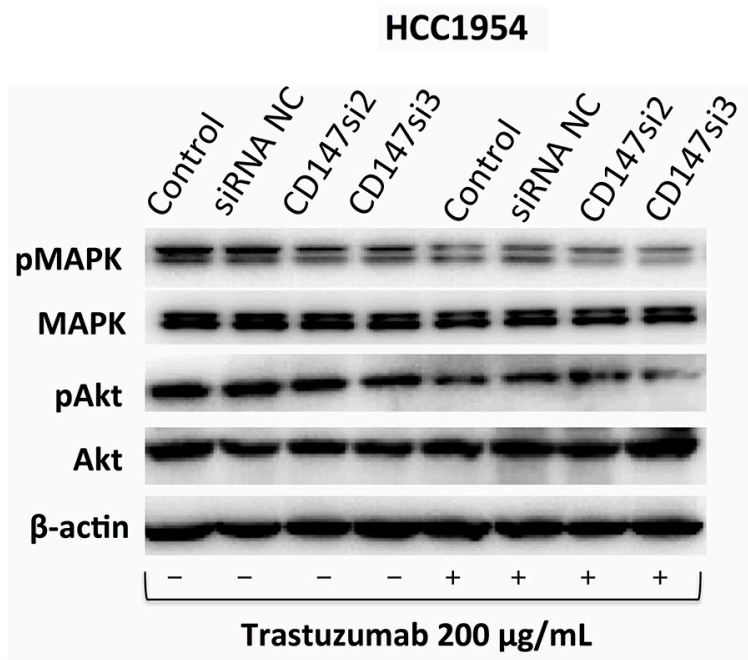

Trastuzumab $200 \mu \mathrm{g} / \mathrm{mL}$ it was even decreased in the parental HCC1954 and MDAMB453 cells, which again may demonstrate that these two cell lines are trastuzumab resistant.

The mechanism underlying the effect of trastuzumab treatment on HER2-positive cancer cells primarily involves the MAPK and Akt pathways [4, $7,8,41]$. CD147 is involved in HCC chemoresistance through the MAPK/Erk signaling pathway, and it activates PI3K/Akt signaling to promote tumor invasion and metastasis [17]. Therefore, we also preliminarily examined changes in MAPK and Akt phosphorylation after CD147 knockdown in the presence or absence of trastuzumab treatment. According to our results, trastuzumab treatment in the control groups decreased MAPK (Thr202/Tyr204) and Akt (Ser473) phosphorylation in SKBR3, BT474 and HCC1954 cells and reduced MAPK phosphorylation in MDA-MB453 cells (which harbor a mutated Akt gene). CD147-

\section{BT474}

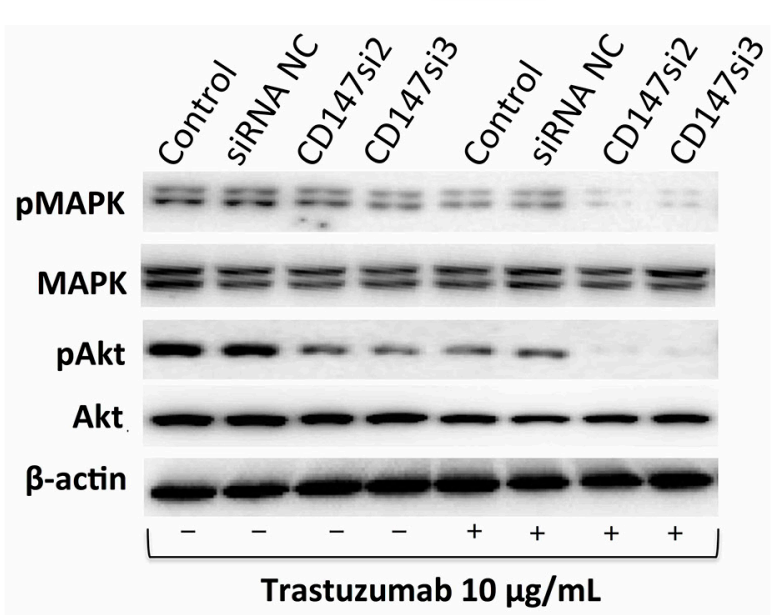

MDA-MB453

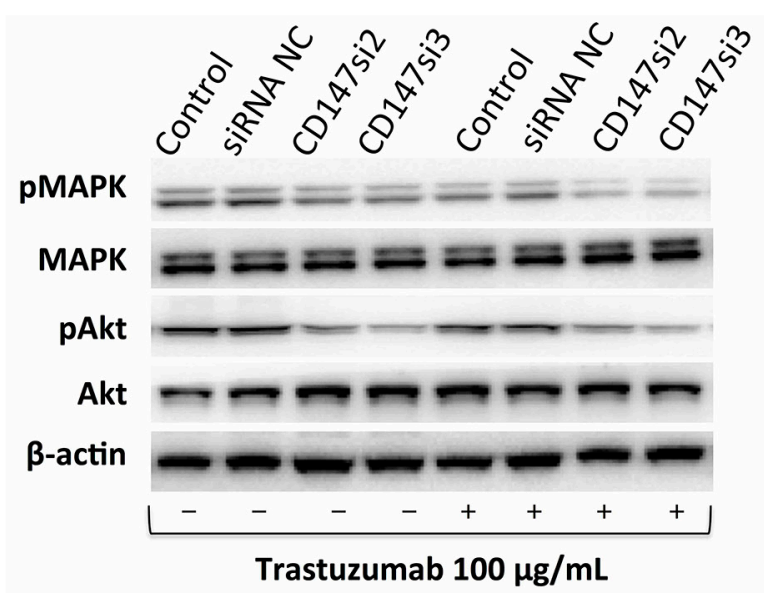

Figure 6: Changes in signaling pathways in different HER2-positive cancer cell lines. The MAPK and Akt pathways and their phosphorylation patterns, as assessed by Western blotting, following trastuzumab treatment for $1 \mathrm{~h}$. The data are presented as the mean of three independent experiments. 
knockdown or CD147-knockdown-plus-trastuzumab treatment reduced MAPK and Akt phosphorylation in all four cell lines compared with the controls, indicating that CD147 knockdown might increase the effects of trastuzumab on the MAPK and Akt pathways in HER2-positive breast cancer cells, and the effects of CD147 knockdown and trastuzumab were overlapping. However, further studies are needed to determine the exact mechanism underlying these effects.

CD147 may be clinically significant not only as a marker of activated regulatory $\mathrm{T}$ cells but also as a potential diagnostic marker of early-stage disease [21] or a prognostic marker, as reported in endometrial cancer [24], gastric cancer [25], HCC [27], lupus nephritis [42] and UCB [28]. CD147 is also an indicator of five-year survival rate in NSCLC [29]. Another study has demonstrated that CD147 expression is associated with poor overall survival in patients with glioblastoma and has suggested that it may be used to predict the treatment response of glioblastoma patients [26]. CD147 expression is correlated with axillary lymph node involvement, TNM (tumor, node, metastasis) staging and breast cancer HER2 expression

A
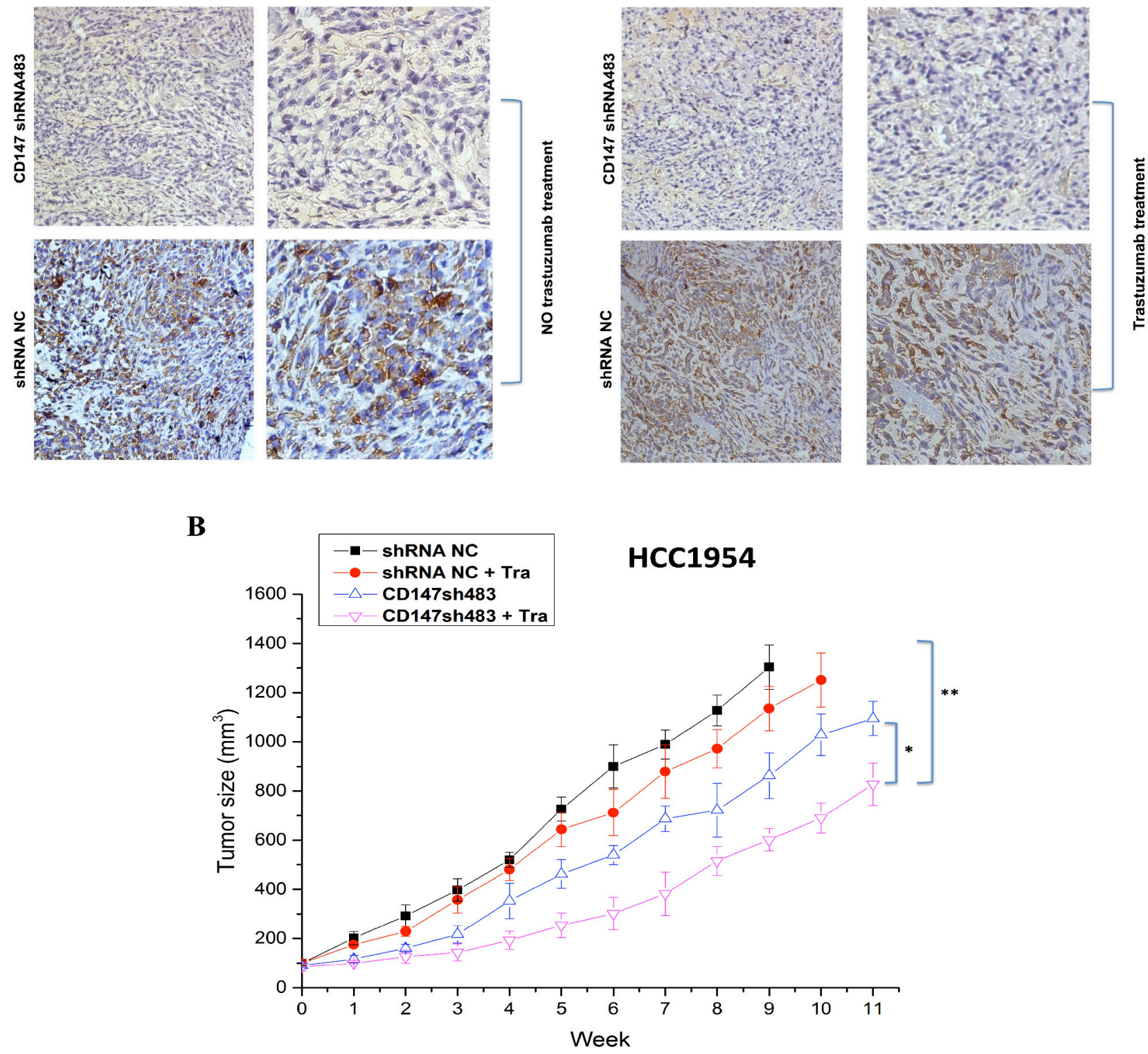

Figure 7: CD147 knockdown inhibits the growth of HER2-positive cancer cells in vivo. A. CD147 expression was decreased in the CD147-knockdown groups with or without trastuzumab treatment, as shown by IHC of mouse tumor tissues. 100× (left) and 400× (right) magnification. B. Tumor volumes of HCC1954 breast tumor xenografts after trastuzumab treatment (10 mg/kg). The data are presented as the mean \pm SEM of three independent experiments. ${ }^{*} \mathrm{p}<0.05$ and $* * \mathrm{p}<0.01$ vs. controls. 
based on S-P IHC analysis $(\mathrm{p}<0.01, \mathrm{p}<0.05$ and $\mathrm{p}<0.01$, respectively) [22]. Our study demonstrated a relationship between CD147 and antibody drug treatment efficacy, but further study of the relationship between CD147 and HER2 is needed. According to our findings, CD147 could serve as a therapeutic target and a potential indicator of the response to trastuzumab treatment and prognosis of HER2-positive breast cancer patients. However, it remains unclear whether high CD147 expression in HER2-positive breast cancer is related to a poor response to antibody drug treatment, and further clinical investigations are needed to confirm this association. The finding that CD147 knockdown may improve antitumor efficacy in patients with HER2-positive solid tumors provides a new strategy for constructing bispecific antibodies against CD147 and HER2 or adding other effective targets, which will be extremely significant for clinical tumor immunotherapy in the future.

\section{MATERIALS AND METHODS}

\section{Cell lines and culture}

The human breast cancer cell lines BT474, SKBR-3, MDA-MB453, HCC1954 and JIMT-1 were purchased from the American Type Culture Collection (ATCC). All cell lines were identified by GENEWIZ, Inc. (Beijing, China) and were maintained in DMEM containing $10 \%$ fetal bovine serum (FBS), except for HCC1954, which was maintained in RPMI 1640 containing $10 \% \mathrm{FBS}$ at $37^{\circ} \mathrm{C}$ in a humidified atmosphere with $5 \% \mathrm{CO}_{2} / 95 \%$ air.

\section{Western blot analysis}

Cells were harvested in RIPA buffer (Beyotime) and maintained on ice. After vortexing for $30 \mathrm{sec}$, the lysates were cleared by centrifugation at $14,000 \mathrm{~g}$ for 5 min. The whole-cell protein extracts were analyzed by Western blotting with the following primary antibodies: CD147 and $\beta$-actin (Abcam), p44/42 MAPK, Akt, phosphorylated p44/42 MAPK (Erk1/2) (p-MAPK, Thr202/Tyr204), phosphorylated Akt (p-Akt, Ser473), Caspase-3, Caspase-9, cleaved Caspase-3 (Asp 175) and 9 (Asp330) and PARP (Asp214) (Cell Signaling Technology).

\section{Determination of cell viability via CCK-8 assay}

Cells were seeded into 96-well plates at a density of $5.0 \times 10^{3}$ cells per well and cultured for $24 \mathrm{~h}$. The cells were treated with Stealth siRNAs for $72 \mathrm{~h}$ in the knockdown groups and/or with different concentrations of trastuzumab (Roche Ltd.) for $96 \mathrm{~h}$ or the otherwise indicated duration. The cells were then incubated with $10 \mu \mathrm{L}$ CCK- 8 solution for $1.5 \mathrm{~h}$ at $37^{\circ} \mathrm{C}$. Absorbance was detected at $450 \mathrm{~nm}$ using a Microplate Reader (Bio-Rad Model 680). The cell survival index was calculated as [A490(trastuzumab+)/ A490(trastuzumab-)] $\cdot 100 \%$.

\section{Determination of cell apoptosis via AV staining}

Control cells or cells treated with $10 \mu \mathrm{g} / \mathrm{mL}$ trastuzumab were collected and stained with AVphycoerythrin and PI (Becton Dickinson). Apoptotic cell death was measured by counting the number of cells that stained positive for AV-phycoerythrin, as determined by FACS.

\section{Immunohistochemistry}

For 3,3-diaminobenzidine staining, paraffinembedded tissue sections were deparaffinized and stained with antibodies against CD147 and HER2 and then with biotin-conjugated secondary antibodies (1:1000), followed by incubation with HRP-conjugated streptavidin (Dianova). The sections were finally counterstained with hematoxylin. The number of tumors in each group was quantified in at least 10 random areas per section. Images were obtained with an OLYMPUS BX51.

\section{In vivo therapeutic analysis}

HCC1954-shRNA NC or HCC1954-sh483 cells (5 $\times 10^{6}$ per mouse) were subcutaneously inoculated into the mammary fat pads of female BALB/c nude mice. When the tumor volumes reached an average of approximately $100 \mathrm{~mm}^{3}$, the mice were randomly divided into groups of 10 mice each. They were then intravenously injected with control human IgG or trastuzumab $(10 \mathrm{mg} / \mathrm{kg})$ twice weekly. Tumors were measured with digital calipers, and tumor volumes were calculated using the formula volume $=[\text { length } \times(\text { width })]^{2} \div 2$.

\section{Statistical analysis}

Experiments were repeated at least three times. Data were analyzed by one-way analysis of variance (ANOVA) or Student's t-test. A p-value of $<0.05$ was considered significant.

\section{ACKNOWLEDGMENTS}

This work was supported by the Natural Science Foundation of China (Nos. 81273311, 31470897, and 81172119).

\section{CONFLICTS OF INTEREST}

The authors declare that there are no conflicts of interest. 


\section{REFERENCES}

1. Slamon DJ, Godolphin W, Jones LA, Holt JA, Wong SG, Keith DE, Levin WJ, Stuart SG, Udove J, Ullrich A, et al. Studies of the HER-2/neu proto-oncogene in human breast and ovarian cancer. Science. 1989; 244: 707-712.

2. Perou CM. Molecular stratification of triple-negative breast cancers. Oncologist. 2010; 15: 39-48.

3. Vogel CL, Cobleigh MA, Tripathy D, Gutheil JC, Harris LN, Fehrenbacher L, Slamon DJ, Murphy M, Novotny WF, Burchmore M, Shak S, Stewart SJ, Press M. Efficacy and safety of trastuzumab as a single agent in first-line treatment of HER2-overexpressing metastatic breast cancer. J Clin Oncol. 2002; 20: 719-726.

4. Nahta R, Yu D, Hung MC, Hortobagyi GN, Esteva FJ. Mechanisms of disease: understanding resistance to HER2targeted therapy in human breast cancer. Nat Clin Pract Oncol. 2006; 3: 269-280.

5. Han S, Meng Y, Tong Q, Li G, Zhang X, Chen Y, Hu S, Zheng L, Tan W, Li H, Chen Y, Zhang G, Li B, et al. The ErbB2-targeting antibody trastuzumab and the smallmolecule SRC inhibitor saracatinib synergistically inhibit ErbB2-overexpressing gastric cancer. MAbs. 2014; 6: 403-408.

6. Simon-Chazottes D, Matsubara S, Miyauchi T, Muramatsu T, Guenet JL. Chromosomal localization of two cell surface-associated molecules of potential importance in development: midkine (Mdk) and basigin (Bsg). Mamm Genome. 1992; 2: 269-271.

7. Kasinrerk W, Fiebiger E, Stefanova I, Baumruker T, Knapp W, Stockinger H. Human leukocyte activation antigen M6, a member of the Ig superfamily, is the species homologue of rat OX-47, mouse basigin, and chicken HT7 molecule. J Immunol. 1992; 149: 847-854.

8. Saxena DK, Oh-Oka T, Kadomatsu K, Muramatsu T, Toshimori K. Behaviour of a sperm surface transmembrane glycoprotein basigin during epididymal maturation and its role in fertilization in mice. Reproduction. 2002; 123: 435-444.

9. Rosenthal EL, Zhang W, Talbert M, Raisch KP, Peters GE. Extracellular matrix metalloprotease inducer-expressing head and neck squamous cell carcinoma cells promote fibroblast-mediated type I collagen degradation in vitro. Mol Cancer Res. 2005; 3: 195-202.

10. Tang J, Guo YS, Zhang Y, Yu XL, Li L, Huang W, Li Y, Chen B, Jiang JL, Chen ZN. CD147 induces UPR to inhibit apoptosis and chemosensitivity by increasing the transcription of Bip in hepatocellular carcinoma. Cell Death Differ. 2012; 19: 1779-1790.

11. Afonso J, Santos LL, Miranda-Goncalves V, Morais A, Amaro T, Longatto-Filho A, Baltazar F. CD147 and MCT1potential partners in bladder cancer aggressiveness and cisplatin resistance. Mol Carcinog. 2014; 54: 1451-1466.
12. Zhou S, Liao L, Chen C, Zeng W, Liu S, Su J, Zhao S, Chen M, Kuang Y, Chen X, Li J. CD147 mediates chemoresistance in breast cancer via ABCG2 by affecting its cellular localization and dimerization. Cancer Lett. 2013; 337: 285-292.

13. Huang Z, Wang L, Wang Y, Zhuo Y, Li H, Chen J, Chen W. Overexpression of CD147 contributes to the chemoresistance of head and neck squamous cell carcinoma cells. J Oral Pathol Med. 2013; 42: 541-546.

14. Wang B, Xu YF, He BS, Pan YQ, Zhang LR, Zhu C, Qu LL, Wang SK. RNAi-mediated silencing of CD147 inhibits tumor cell proliferation, invasion and increases chemosensitivity to cisplatin in SGC7901 cells in vitro. J Exp Clin Cancer Res. 2010; 29: 61.

15. Li QQ, Wang WJ, Xu JD, Cao XX, Chen Q, Yang JM, Xu ZD. Involvement of CD147 in regulation of multidrug resistance to P-gp substrate drugs and in vitro invasion in breast cancer cells. Cancer Sci. 2007; 98: 1064-1069.

16. Toole BP, Slomiany MG. Hyaluronan, CD44 and Emmprin: partners in cancer cell chemoresistance. Drug Resist Updat. 2008; 11: 110-121.

17. Jia L, Xu H, Zhao Y, Jiang L, Yu J, Zhang J. Expression of CD147 mediates tumor cells invasion and multidrug resistance in hepatocellular carcinoma. Cancer Invest. 2008; 26: 977-983.

18. Hao J, Chen H, Madigan MC, Cozzi PJ, Beretov J, Xiao W, Delprado WJ, Russell PJ, Li Y. Co-expression of CD147 (EMMPRIN), CD44v3-10, MDR1 and monocarboxylate transporters is associated with prostate cancer drug resistance and progression. Br J Cancer. 2010; 103: 1008-1018.

19. Chen H, Wang L, Beretov J, Hao J, Xiao W, Li Y. Co-expression of CD147/EMMPRIN with monocarboxylate transporters and multiple drug resistance proteins is associated with epithelial ovarian cancer progression. Clin Exp Metastasis. 2010; 27: 557-569.

20. Kang MJ, Kim HP, Lee KS, Yoo YD, Kwon YT, Kim KM, Kim TY, Yi EC. Proteomic analysis reveals that CD147/ EMMPRIN confers chemoresistance in cancer stem celllike cells. Proteomics. 2013; 13: 1714-1725.

21. Xiong L, Edwards CK, 3rd, Zhou L. The biological function and clinical utilization of CD147 in human diseases: a review of the current scientific literature. Int J Mol Sci. 2014; 15: 17411-17441.

22. Xue S LS, Wu ZS, Wang XN, Wu Q, Yang F. Expression of CD147, matrix metalloproteinases and transforming growth factor beta1 in breast cancer. Zhonghua Bing Li Xue Za Zhi. 2009; 38: 524-528.

23. Liu F, Cui L, Zhang Y, Chen L, Wang Y, Fan Y, Lei T, Gu F, Lang R, Pringle GA, Zhang X, Chen Z, Fu L. Expression of $\mathrm{HAb} 18 \mathrm{G}$ is associated with tumor progression and prognosis of breast carcinoma. Breast Cancer Res Treat. 2010; 124: 677-688. 
24. Nakamura K, Kodama J, Hongo A, Hiramatsu Y. Role of emmprin in endometrial cancer. BMC Cancer. 2012; 12: 191.

25. Shou ZX, Jin X, Zhao ZS. Upregulated expression of ADAM17 is a prognostic marker for patients with gastric cancer. Ann Surg. 2012; 256: 1014-1022.

26. Yang M, Yuan Y, Zhang H, Yan M, Wang S, Feng F, Ji P, Li Y, Li B, Gao G, Zhao J, Wang L. Prognostic significance of CD147 in patients with glioblastoma. J Neurooncol. 2013; 115: 19-26.

27. Zhu S, Li Y, Zhang Y, Wang X, Gong L, Han X, Yao L, Lan M, Zhang W. Expression and clinical implications of HAb18G/CD147 in hepatocellular carcinoma. Hepatol Res. 2015; 45: 97-106.

28. Bhagirath D, Abrol N, Khan R, Sharma M, Seth A, Sharma A. Expression of CD147, BIGH3 and Stathmin and their potential role as diagnostic marker in patients with urothelial carcinoma of the bladder. Clin Chim Acta. 2012; 413: 1641-1646.

29. Xu XY, Zhi C, Li YM, Qi WJ, Mei JJ, Yan ZM, Shen H. [Association of HAb18G with clinicopathologic features and prognosis in non-small cell carcinoma of lung]. Zhonghua Bing Li Xue Za Zhi. 2012; 41: 151-155.

30. Xu J, Lu Y, Qiu S, Chen ZN, Fan Z. A novel role of EMMPRIN/CD147 in transformation of quiescent fibroblasts to cancer-associated fibroblasts by breast cancer cells. Cancer Lett. 2013; 335: 380-386.

31. Ke X, Chen Y, Wang P, Xing J, Chen Z. Upregulation of CD147 protects hepatocellular carcinoma cell from apoptosis through glycolytic switch via HIF-1 and MCT-4 under hypoxia. Hepatol Int. 2014; 8: 405-414.

32. Wu J, Li Y, Dang YZ, Gao HX, Jiang JL, Chen ZN. HAb18G/CD147 promotes radioresistance in hepatocellular carcinoma cells: a potential role for integrin beta1 signaling. Mol Cancer Ther. 2015; 14: 553-563.

33. Zhang X, Tang X, Liu H, Li L, Hou Q, Gao J. Autophagy induced by baicalin involves downregulation of CD147 in SMMC-7721 cells in vitro. Oncol Rep. 2012; 27: 1128-1134.

34. Dean NR, Knowles JA, Helman EE, Aldridge JC, Carroll WR, Magnuson JS, Clemons L, Ziober B, Rosenthal EL. Anti-EMMPRIN antibody treatment of head and neck squamous cell carcinoma in an ex-vivo model. Anticancer Drugs. 2010; 21: 861-867.

35. Xu X LS, Lei B, Li W, Lin N, Sheng W, Huang A, Shen H. Expression of HAb18G in non-small lung cancer and characterization of activation, migration, proliferation, and apoptosis in A549 cells following siRNA-induced downregulation of HAb18G. Mol Cell Biochem. 2013; 383: 1-11.

36. Zhao Y, Chen S, Gou WF, Niu ZF, Zhao S, Xiao LJ, Takano Y, Zheng HC. The role of EMMPRIN expression in ovarian epithelial carcinomas. Cell Cycle. 2013; 12: 2899-2913.

37. Gao H, Jiang Q, Han Y, Peng J, Wang C. shRNAmediated EMMPRIN silencing inhibits human leukemic monocyte lymphoma U937 cell proliferation and increases chemosensitivity to adriamycin. Cell Biochem Biophys. 2015; 71: 827-835.

38. Bougatef F, Menashi S, Khayati F, Naimi B, Porcher R, Podgorniak MP, Millot G, Janin A, Calvo F, Lebbe C, Mourah S. EMMPRIN promotes melanoma cells malignant properties through a HIF-2alpha mediated up-regulation of VEGF-receptor-2. PLoS One. 2010; 5: e12265.

39. Han X, Zhang X, Li H, Huang S, Zhang S, Wang F, Shi Y. Tunicamycin enhances the antitumor activity of trastuzumab on breast cancer in vitro and in vivo. Oncotarget. 2015; 6: 38912-38925. doi: 10.18632/oncotarget.5334.

40. Chakraborty AK, Mehra R, Digiovanna MP. Co-targeting ER and HER family receptors induces apoptosis in HER2normal or overexpressing breast cancer models. Anticancer Res. 2015; 35: 1243-1250.

41. Feldinger K, Generali D, Kramer-Marek G, Gijsen M, Ng TB, Wong JH, Strina C, Cappelletti M, Andreis D, Li JL, Bridges E, Turley H, Leek R, et al. ADAM10 mediates trastuzumab resistance and is correlated with survival in HER2 positive breast cancer. Oncotarget. 2014; 5: 6633-6646. doi:10.18632/ oncotarget.1955.

42. Maeda-Hori M, Kosugi T, Kojima H, Sato W, Inaba S, Maeda K, Nagaya H, Sato Y, Ishimoto T, Ozaki T, Tsuboi N, Muro Y, Yuzawa Y, et al. Plasma CD147 reflects histological features in patients with lupus nephritis. Lupus. 2014; 23 : 342-352. 